\title{
The Potential Protective Effect of Ferulic Acid against Gamma Irradiation Induced Ovarian Failure in Rats
}

\author{
Salma M. Abdel Fattah, Heba Karam Mohmed", Marwa Abd El Hameed Mohamed \\ Department of Drug Radiation Research, National Center for Radiation Research \\ and Technology (NCRRT), Atomic Energy Authority (AEA), Cairo, Egypt.
}

$\mathbf{T}$

HIS STUDY aims to evaluate the radioprotective effect of Ferulic acid (FA) against ovarian damage in premature female rats. Four groups of female rats were used (ten rats in each group). Group (1): Control, Group (2): Irradiation (IRR) (rats were exposed to 4Gy of whole body gamma irradiation as a single dose), Group (3): FA (rats received $50 \mathrm{mg} / \mathrm{kg}$ b.wt of Ferulic acid orally for two weeks) and Group (4): FA+IRR (rats received Ferulic acid as group 3 then exposed to $4 \mathrm{~Gy}$ as group2). The rats were sacrificed after $24 \mathrm{~h}$ of irradiation. The level of FSH, LH, and $\mathrm{E}_{2}$ were estimated in the serum. The level of $\mathrm{H}_{2} \mathrm{O}_{2}$ and GPx activity and the gene expression of cytochrome C, P53 and caspase 3 were evaluated in ovarian tissue. Histopathological examination of the ovary and uterus tissues was performed. The results revealed that gamma irradiation caused an elevation in $\mathrm{FSH}, \mathrm{LH}, \mathrm{H}_{2} \mathrm{O}_{2}$, cytochrome $\mathrm{C}, \mathrm{P} 53$ and caspase 3 and a decline in $\mathrm{E}_{2}$ and GPx. The administration of FA prior gamma irradiation led to an improvement in female hormones, $\mathrm{H}_{2} \mathrm{O}_{2}$, GPx and apoptotic markers and matched the histopathological examination results. It could be concluded that Ferulic acid may exert a radioprotective effect against irradiation induced apoptosis in the ovary of rats and alteration in the level of serum female hormones.

Keywords: Ferulic, Irradiation, Ovarian failure, Apoptosis.

\section{Introduction}

Gamma radiation is responsible for many dangerous influences on living tissue, such as DNA damage, apoptosis and inflammation, mainly through the generation of reactive oxygen species (ROS). Radiolysis of water generates ROS, which primarily consists of hydroxyl radical, superoxide anion and hydroperoxyl (Sinha et al., 2012).

Ionizing radiation is used for radiation therapy, a form of cancer treatment that kills cancer cells and reduces tumor size. It also leads to destroying the normal cells by damaging their genetic materials, making it impossible for these cells to continue their growth and division. Although radiation damages both cancer cells and normal cells, the main target of radiation therapy is to kill as many cancer cells as possible while limiting the damage to nearby healthy tissue (Grdina et al., 2002).

The harmful effects of ionizing radiation on the biological systems are mediated through the generation of ROS including superoxide anion, hydroxyl radical $(\mathrm{OH})$ and hydrogen peroxide $\mathrm{H}_{2} \mathrm{O}_{2}$. These ROS are the reason for oxidative stress in many critical cellular molecules such as DNA, proteins and lipid membranes (Sőnmezer \& Oktay, 2008). Radiation-induced oxidative damage may cause a chromosomal aberration, lipid peroxidation and alterations in endogenous antioxidants (Nair et al., 2001).

Ionizing radiation, including gamma and $\mathrm{X}$-ray, is considered one of the important etiologies for infertility. An increasing risk of infertility and abortion was found in the pregnant women who work in the nuclear field (Dehghan et al., 2014). Moreover, women who received pelvic radiation during childhood were at a high risk of acute ovary failure and/or premature menopause(Green et al., 2009).

Adult females who received radiotherapy are at a high risk of oocyte loss and reduction in follicle store (Sőnmezer \& Oktay, 2008). In addition, the impairment of ovaries induced by ionizing 
radiation was shown by in vivo observation. Searching for more effective radioprotectors has drawn a wide attention to the women of childbearing age who may be exposed to ionizing radiation such as radiotherapy (Said et al., 2012).

Many synthetic radioprotectors such as lipoic acid, deoxspergualin, cysteine, cysteamine, 2-mercaptopropionyglycine (2MPG), amifostine(2-(3-aminopropylamino) ethyl sulphanylphosphonic acid) were tested and found to be proper radioprotectors. However, their practical application is limited by the high systemic toxicity at their optimum protective dose. Thus, seeking less or non-toxic compounds from biological originsuch as polyphenols (hydroxybenzoic acids, hydroxycinnamic acids, anthocyanins, proanthocyanidins, flavonoids, stilbenes and lignans) is of utmost importance $(\mathrm{Ou}$ \& Kwok, 2004).

Ferulic acid (FA) is a ubiquitous plant constituent that comes from the metabolism of phenylalanine and tyrosine. It is found in leaves and seeds, both in its free form and covalently linked to lignin and other biopolymers. FA is also a major constituent of some fruits such as orange and in some vegetables, for instance, tomato, carrot and sweet corn. In wheat, FA is ester related to cell wall carbohydrates in the alcurone, pericarp and embryo cell wall. $90 \%$ of the total phenolic acids in common flour is being predominated through transisomer (Fulcher, 1983).

Ferulic acid (hydroxycinnamic acid) is usually found in wheat, rice, and broccoli. It has a heavy in vitro antioxidant property which includes very high DPPH (2,2-diphenyl-1-picrylhydrazyl) radical scavenging activity, and hydroxyl radical scavenging. It is considered one of the best choices due to its low cost, higher bioavailability, and low toxicity. Therefore,ferulic acid has a very promising in vitro antioxidant activity (Das et al., 2014).

It has been reported that pretreatment with ferulic acid of $\gamma$-irradiated lymphocytes caused a decreased lipid peroxidation and better antioxidant status preventing lymphocytes damage whch is mainly attributed to its antioxidant sparing action that prevents the formation of ROS. FA scavenges superoxide anion radical and prevents lipid peroxidation in an action similar to superoxide dismutase (SOD). In addition, it has an antioxidant activity, FA modulate phase 2 enzymes such as glutathione s-transferase (GST). It has been shown that FA induces intrinsic antioxidant dismutase, catalase and glutathione reductase activities. Accordingly, the radioprotective action of FA could be assigned to the up regulation of antioxidant enzymes (Srinivasan et al., 2007).

This work is designed to evaluate the radioprotective effect of Ferulic acid on gamma irradiation induced premature ovarian failure via the assessment of serum FSH, LH, and E2, in addition to the estimation of $\mathrm{H}_{2} \mathrm{O}_{2}$ and GPx and the gene expression of some apoptotic markers in the ovarian tissue.

\section{Materials and Methods}

\section{Animals}

Fourty female albino rats with an average weight of 40-50gm (23-26 days old) were obtained from the animal house belonging to the NCRRT, Atomic Energy Authority, Cairo, Egypt. Rats were housed in regular designed cages and maintained in a good ventilation, at a temperature of $25^{\circ} \mathrm{C} \pm 5^{\circ} \mathrm{C}, 60 \%$ humidity, with suitable illumination conditions $(12 \mathrm{~h} / 12 \mathrm{~h}$ light/dark cycle) and were allowed standard pellet diet and fresh water ad libitum. Animals were left oneweek for acclimatization on lab environment before starting the onset of the experiment. Animal care and the protocol of animal treatment were approved by the Animal Care Committee of the NCRRT, Cairo, Egypt and in accordance with the international recommendations of the proper care and use of laboratory animals.

\section{Ferulic acid treatment}

Ferulic acid (FA) was obtained from Sigma Chemical Co. (St. Louis, MO) USA. FA was dissolved in distilled water and given to rats orally at a doe of $50 \mathrm{mg} / \mathrm{kg} \mathrm{b}$.wt/day for two weeks (Roy et al., 2013).

\section{Irradiation facilities}

Rats were exposed to 4Gy whole body gamma irradiation. Irradiation was carried out at the Canadian Gamma Cell-40 (137Cs) located at NCRRT, Cairo, Egypt. The dose rate was $0.675 \mathrm{~Gy} / \mathrm{min}$.

\section{Experimental design}

Rats were randomly divided into four groups (10 in each group). Group 1: Control rats without 
treatment. Group 2: (IRR) rats were exposed to 4Gy whole body gamma irradiation (Ibrahim et al., 2015). Group 3: (FA) rats received Feulic acid (50mg/kg b.wt) orally daily for two weeks (Roy et al., 2013). Group 4: (FA+IRR) rats received Feulic acid $(50 \mathrm{mg} / \mathrm{kg} \mathrm{b}$. wt) orally daily for two weeks, then exposed to gamma irradiation as in Group 2.

Rats were sacrificed $24 \mathrm{~h}$ post irradiation under light anesthesia usingurethane $(1.2 \mathrm{mg} / \mathrm{kg})$ (Flecknell, 1987). Blood samples were collected into plain test tubes for serum separation for biochemical analysis. Ovaries and uterus were dissected out, washed with saline, dried on a filter paper and weighted. Three ovaries and uteri from each group were fixed at $10 \%$ buffered neutral formalin for morphometric and histopathological examinations while the others were kept at $-20^{\circ} \mathrm{C}$ till being used for biochemical analysis and gene expression determination.

Biochemical parameters investigated in serum

Follicle stimulating hormone (FSH), Luteinizing hormone (LH) and Estradiol (E2) were determined using the available commercial kits Rat ELISA, purchased from MyBiosourceCo., the United States of America.

Biochemical parameters investigated in the ovarian homogenate

Hydrogen peroxide $\left(\mathrm{H}_{2} \mathrm{O}_{2}\right)$ was estimated according to Fossati et al. (1983) and glutathione peroxidase (GPx) was measured according to Paglia \& Valentine (1967).

RNA extraction and RT-PCR analysis of cytochrome C, P53 and caspase 3

Total RNA was isolated from ovarian tissue homogenate using RN easy Purification Reagent (Qiagen, Valencia, California) according to the manufacturer's protocol. Extracted RNA was quantified using spectrophotometer at $260 \mathrm{~nm}$. Reverse transcription was carried out on $5 \mu \mathrm{g}$ RNA from each sample using MMuLV reverse transcriptasein a $50 \mu \mathrm{L}$ reaction volume. Mixtures of the reverse transcription were used for amplification of fragments specific for cytochrome C, P53, and caspase 3 by PCR using the primer pairs listed in Table 1 .

The levels of expression of all transcripts were normalized to that of glyceraldehyde-3phosphate dehydrogenase (GAPDH) mRNA in the same tissue sample. The real time PCR was performed using the Quanti Tect SYBR Green PCR Kit (Qiagen, Germany) according to the manufacturer's instructions, by Applied Biosystems 7500 Instrument, USA. The PCR reaction mix was carried out in a total volume of $25 \mu \mathrm{L}$, containing $2 \times$ Quanti Tect SYBR Green PCR master mix, $20 \mathrm{pmol} / \mu \mathrm{L}$ specific primer. Subsequently, cDNA was synthesized from the purified RNA.

TABLE 1. The primer pairs of GADPH, cytochrome c, P53 and caspase3.

\begin{tabular}{ll}
\hline Genes & \multicolumn{1}{c}{ Primer } \\
\hline \multirow{3}{*}{ GADPH } & 5'-CTCCCATTCTTCCACCTTTG-3' \\
& Reverse primer: \\
& 5'-CTTGCTCTCAGTATCCTTGC-3' \\
\hline & Forward primer: \\
Cytochrome C & 5'-TTTGGATCCAATGGGTGATGTTGAG-3' \\
& Reverse primer \\
& 5'TTTGAATTCCTCATTAGTAGCTTTTTTGAG-3' \\
& Forward primer: \\
P53 & 5'- CGCAAAAGAAGAAGCCACTA-3' \\
& Reverse primer: \\
& 5'-TCCACTCTGGGCATCCTT-3' \\
\hline & Forward primer: \\
Caspase3 & 5'- ACTCTTGTGGGCAAACCCAA -3' \\
& Reverse primer: \\
& 5'-CTCTCCATGAGCAGTAGCCG -3'
\end{tabular}


The protocol consisted of 45 amplification cycles, each conducted as follows; $10 \mathrm{~min}$ at $95^{\circ} \mathrm{C}$ (holding stage), $15 \mathrm{sec}$ for denaturation at $95^{\circ} \mathrm{C}$, $30 \mathrm{sec}$ for annealing at $60^{\circ} \mathrm{C}$ and another $15 \mathrm{sec}$ for elongation at $60^{\circ} \mathrm{C}$. The sequences of PCR primer pairs used for each gene are shown in Table 1. Data were analyzed usingthe ABI Prism sequence detection system software and quantified using the v1.7 Sequence Detection Software from PE Biosystems (Foster City, CA). The relative expression of studying genes was calculated using the comparative threshold cycle method. All values were normalized to the GADPH genes as an invariant endogenous control (reference gene). The relative quantification was then calculated by the expression $2^{-\Delta \Delta C t}$ (Pfaffl, 2001).

\section{Histopathological examination}

Autopsy samples were taken from the ovary and uterus of rats in different groups and fixed in $10 \%$ formalin for $24 \mathrm{~h}$. Washing was done with tap water and then serial dilutions of alcohol (methyl, ethyl and absolute ethyl) were used for dehydration. Specimens were cleared in xylene and embedded in paraffin at 56 degrees in a hot air oven for $24 \mathrm{~h}$. Paraffin bees wax tissue blocks were prepared for sectioning at 4 microns thickness. The obtained tissue sections were collected on glass slides, deparaffinized and stained by hematoxylin $\&$ eosin stain for examination through the light electric microscope (Banchroft et al., 1996).

\section{Morphometric analysis of follicles population}

Ovaries were collected and prepared as described above, using light microscope. Follicles were classified depending on their follicular development. Follicles were categorized as primordial if they contained an oocyte surrounded by a single layer of spindle-shaped granulosa cells. Follicles were classified as preantral if they contained an oocyte with a visible nucleolus, more than one layer and less than five layers of granulosa cells and lacked an antral space. Follicles were classified as antral if they contained an oocyte with a visible nucleolus, more than five layers of granulosa cells and/or an antral space as described previously (Britt et al., 2000). Atretic follicles were identified due to the presence of a degenerating oocyte or pyknotic granulosa cells (Braw \& Tsafriri, 1980).

\section{$\underline{\text { Results }}$}

Data in Table 2 show that there was no significant change in the body weight of the irradiated rats compared to the control. While FA and FA+IRR groups recorded a significant elevation in body weight compared to the control. The body weight of FA+IRR group was also significantly higher than in their radiated group. On the other hand, the relative ovary \& uterus weights were reduced significantly post irradiation when compared to the control group. FA treatment has lowered the relative ovary weight while increased the relative uterus weight regarding their respective control levels. FA administration prior irradiation ameliorated the relative ovary weight and significantly increased the relative uterus weight compared to the irradiated group.

TABLE 2. Effect of Ferulic acid on body weight, relative ovary weight and relative uterus weight in irradiated female rats.

\begin{tabular}{|c|c|c|c|}
\hline Groups & $\begin{array}{l}\text { Body weight } \\
\text { (gm) }\end{array}$ & Relative ovary weight (mg) & Relative uterus weight (mg) \\
\hline Control (mean \pm S.E) & $49.80 \pm 2.47$ & $119 \pm 0.018$ & $141.4 \pm 0.006$ \\
\hline IRR (mean \pm S.E) & $49.80 \pm 1.33$ & $43 \pm 0.002^{*}$ & $66.5 \pm 0.004^{*}$ \\
\hline $\mathrm{FA}(\mathrm{mean} \pm \mathrm{S} . \mathrm{E})$ & $80.30 \pm 2.56^{*}$ & $92 \pm 0.005$ & $203 \pm 0.016$ \\
\hline $\mathrm{FA}+\mathrm{IRR}($ mean \pm S.E) & $83.70 \pm 3.80^{*, \#}$ & $82 \pm 0.007$ & $182.5 \pm 0.020^{*, \#}$ \\
\hline
\end{tabular}

The relative ovary and uterus weights were stated by one-way ANOVA (non parametric) using Kruskal- Wallis test.

*: Significantly different from control, \#: Significantly different from IRR, $\mathrm{P}<0.05 \mathrm{n}=7$. 
FSH and LH concentrations showed a significant elevation in irradiated group and compared to the control level. On the other hand, administration of FA before irradiation has attenuated the increase of FSH and LH that donot reach the control level. While $\mathrm{E}_{2}$ recorded a significant decrease in the irradiated group compared to the control level. The administration of FA prior to the irradiation has significantly increased the level of $\mathrm{E}_{2}$ compared to the irradiated group, but was still below the normal level (Table 3).

The results shown in Table 4, revealed that there was a significant increment in hydrogen peroxide concentration while, glutathione peroxidase activity recorded a significant decrease post- irradiation compared to the control level.
Moreover, FA group showed a significant increase in $\mathrm{H}_{2} \mathrm{O}_{2}$ concentration and a significant decrease in GPx activity compared to the control group. On the other hand, administration of FA prior the exposure of irradiation led to the restoration in hydrogen peroxide level and improved the activity of glutathione peroxidase.

Table 5 show that there was a significant up regulation of the gene expression of cytochrome $\mathrm{C}$, p53 and caspase 3 post- irradiation and administration of FA alone compared to the control level. On the contrary, irradiated rats treated with FA recorded a significant down regulation of the gene expression of cytochrome C, p53 and caspase 3 compared to the irradiated group.

TABLE 3. Effect of Ferulic acid on serum FSH, LH and E2 in irradiated female rats.

\begin{tabular}{|c|c|c|c|}
\hline Groups $\quad$ Parameters & $\begin{array}{c}\text { FSH } \\
\text { (ng/g tissue) }\end{array}$ & $\begin{array}{c}\text { LH } \\
\text { (ng/g tissue) }\end{array}$ & $\begin{array}{c}\text { E2 } \\
\text { (pg/g tissue) }\end{array}$ \\
\hline Control (mean \pm S.E) & $3.45 \pm 0.290$ & $3.45 \pm 0.156$ & $8.324 \pm 0.123$ \\
\hline IRR $($ mean \pm S.E) & $16.65 \pm 1.588^{*}$ & $21.65 \pm 1.409^{*}$ & $2.65 \pm 0.111^{*}$ \\
\hline FA $($ mean \pm S.E $)$ & $12.27 \pm 1.051^{*}$ & $13.65 \pm 0.246^{*}$ & $7.45 \pm 0.067$ \\
\hline $\mathrm{FA}+\mathrm{IRR}($ mean \pm S.E $)$ & $13.23 \pm 0.382^{*}$ & $13.65 \pm 0.559^{* * \#}$ & $6.80 \pm 0.364^{* * \#}$ \\
\hline
\end{tabular}

Statistical analysis was carriedoutby one way ANOVA followed by Tukey- Kramer Multiple Comparison Test.

*: Significantly different from control, \#: Significantly different from IRR, $\mathrm{P}<0.05, \mathrm{n}=7$.

TABLE 4. Effect of Ferulic acid on ovarian $\mathrm{H}_{2} \mathrm{O}_{2}$ level and GPx activity in irradiated female rats.

\begin{tabular}{|c|c|c|}
\hline Groups $\quad$ Parameters & $\begin{array}{c}\mathrm{H}_{2} \mathrm{O}_{2} \\
(\mathrm{nmol} / \mathrm{g} \text { tissue })\end{array}$ & $\begin{array}{c}\text { GPx } \\
(\mathrm{mU} / \mathrm{g} \text { tissue) }\end{array}$ \\
\hline Control $($ mean \pm S.E) & $6.164 \pm 0.062$ & $72.40 \pm 1.17$ \\
\hline IRR $($ mean \pm S.E) & $43.24 \pm 0.872^{*}$ & $24.37 \pm 1.70^{*}$ \\
\hline $\mathrm{FA}($ mean \pm S.E $)$ & $11.00 \pm 0.939^{*}$ & $49.27 \pm 2.90^{*}$ \\
\hline $\mathrm{FA}+\mathrm{IRR}($ mean \pm S.E) & $8.840 \pm 0.603^{\#}$ & $52.23 \pm 1.39^{*, \#}$ \\
\hline
\end{tabular}

Statistical analysis was carriedoutby oneway ANOVA followedby Tukey- Kramer Multiple ComparisonTest.

*: Significantly different from control, \#: Significantly different from IRR, $\mathrm{P}<0.05, \mathrm{n}=7$. 
TABLE 5. Effect of Ferulic acid on ovarian relative gene expression of cytochrome c, P53 and caspase 3 in irradiated female rats.

\begin{tabular}{llll}
\hline Groups & Parameters & P53 & Caspase3 \\
\hline
\end{tabular}

Control (mean \pm S.E)

$1.006 \pm 0.004$

$1.00 \pm$ zero

$2.10 \pm 0.063$

IRR (mean \pm S.E)

$8.25 \pm 0.648^{*}$

$17.45 \pm 1.722^{*}$

$12.05 \pm 0.827^{*}$

FA $($ mean \pm S.E $)$

$3.26 \pm 0.107^{*}$

$8.132 \pm 0.460^{*}$

$7.40 \pm 0.089$

$\mathrm{FA}+\mathrm{IRR}(\mathrm{mean} \pm \mathrm{S} . \mathrm{E})$

$5.169 \pm 0.384^{* * \#}$

$5.06 \pm 0.074^{* * \#}$

$3.35 \pm 0.079^{\#}$

Statistical analysis was carried out by one way ANOVA followed by Tukey- Kramer Multiple Comparison Test.

*: Significantly different of control, \#: Significantly different of IRR, $\mathrm{P}<0.05, \mathrm{n}=7$.

There was a decrease in the number of primordial, preantral and antral follicles of the irradiated group compared to the control group, while the atertic follicles recorded an increment. Pretreatment of Ferulic acid in irradiated rats caused an improvement in the number of all different types of follicles (Fig.1). On the other hand, the values in the FA alone group were nearly similar to their respective values in the control group.
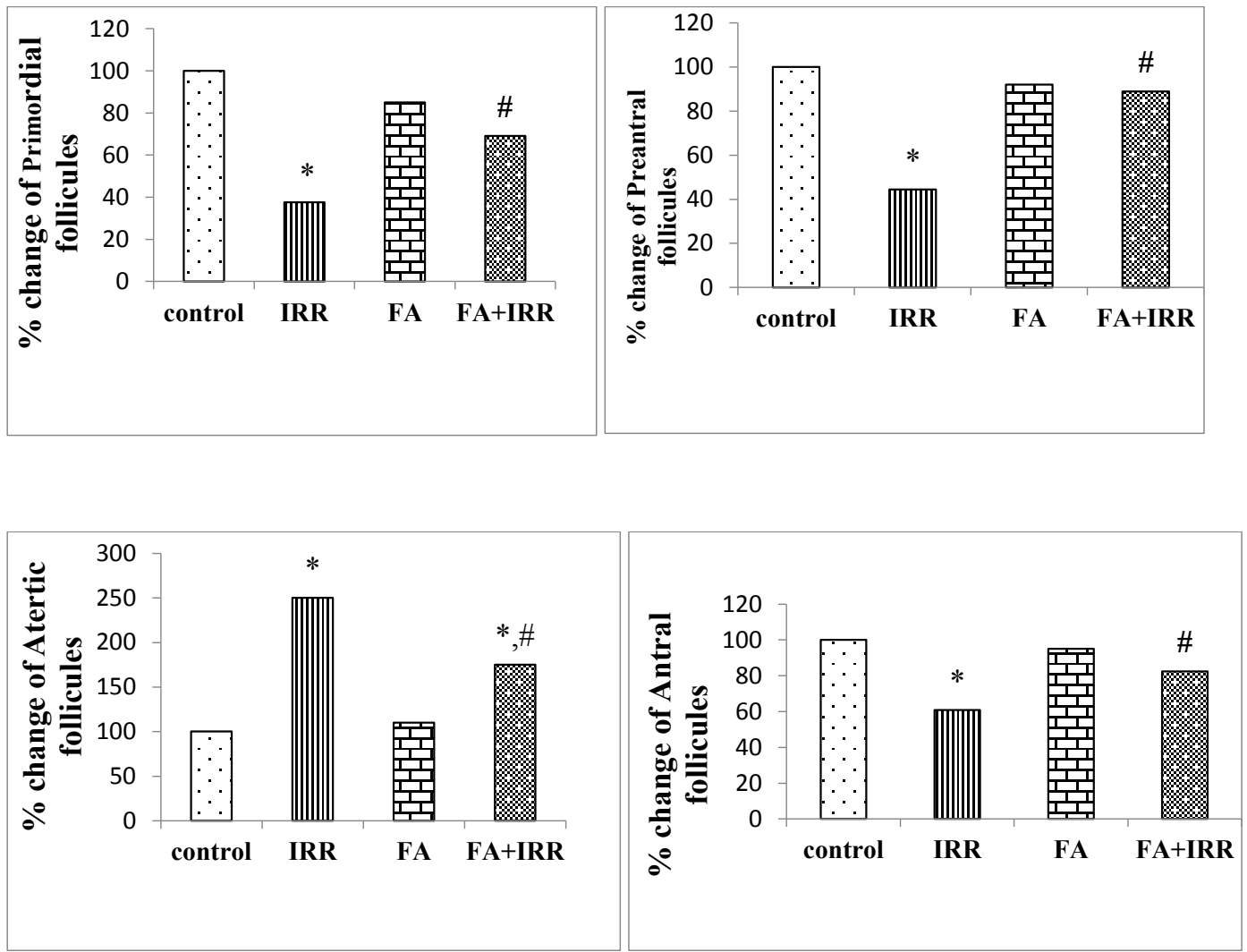

Fig. 1. Morphometric analysis of ovarian follicle population numbers primordial, preantral, atretic and antral were expressed as a percentage (\%) of control [Data represented as \% change of the control in each type, $n=3$ ]. 


\section{Histopathological Examination}

Figure 2 A shows that the ovary of rat in the control group shows a normal histological structure of the different stages of the follicular maturation with corpus luteum. While the ovary of the irradiated group (Fig. 2 B) showed multiple numbers of mature nonovulated follicles without corpus luteum detected in the cortical portion. On the other hand, the ovaries of FA\&FA+IRR groups showed that there were
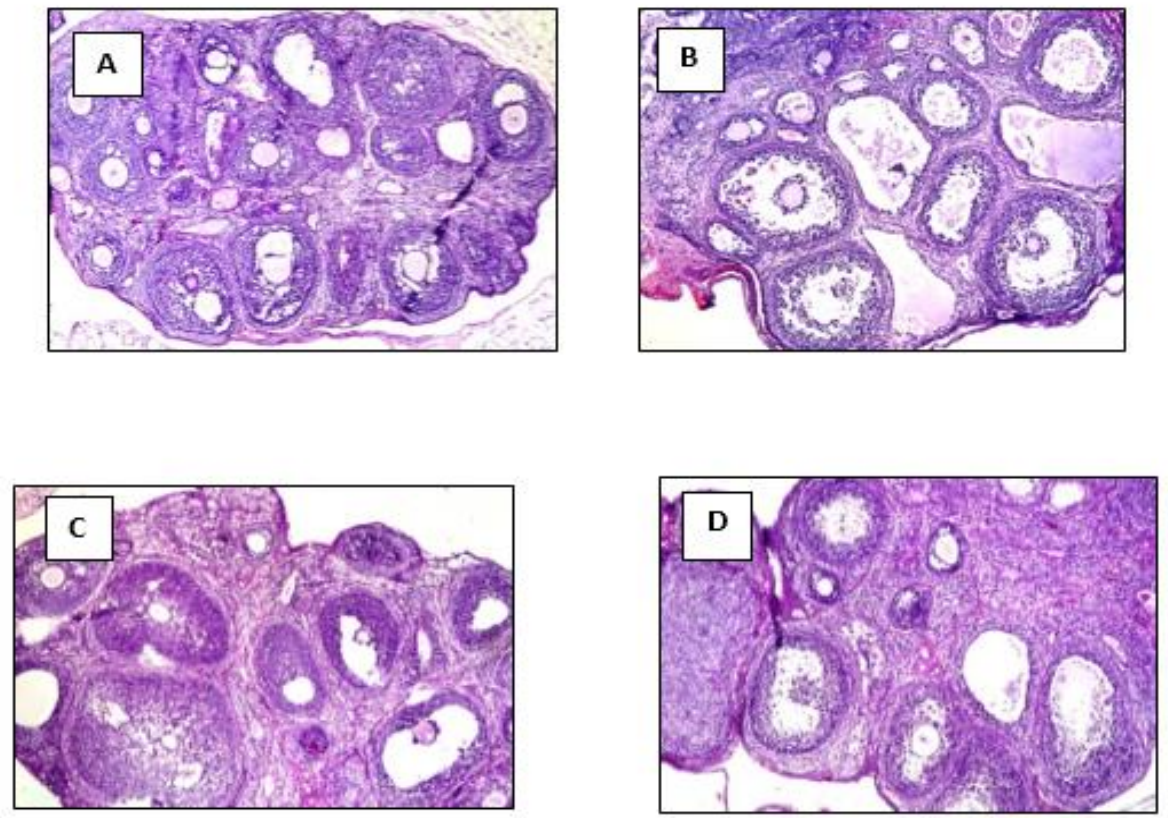

Fig. 2. Histological structure of ovary in all different groups [A: Control, B: IRR, C: FA, D: FA+IRR (H\&E x16)].
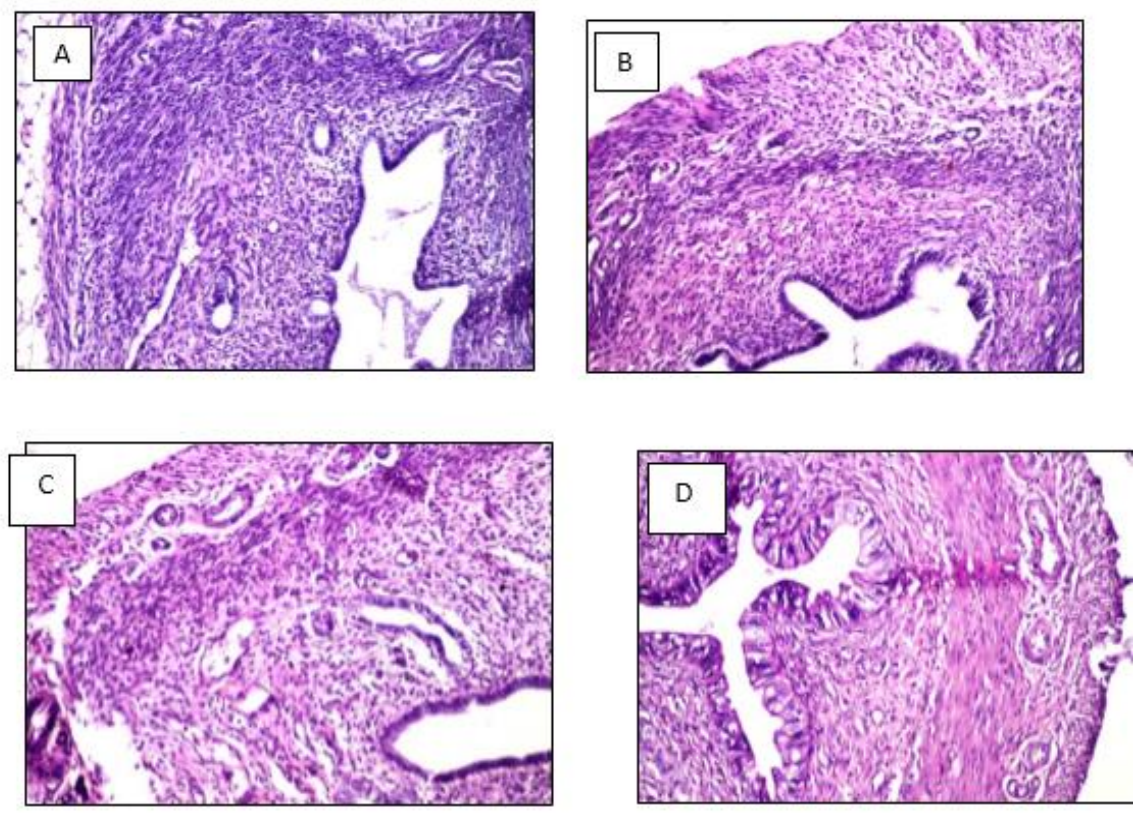

Fig. 3. Histological structure of uterus in all different groups [A: Control, B: IRR, C: FA, D: FA+IRR (H\&E x16). 


\section{Discussion}

Primary ovarian failure (POF) is the loss of ovarian function resulted from a process directly affecting the ovaries. Multimodal cancer treatment and other processes, including autoimmunity, chromosomal abnormalities and natural aging may cause a secondary ovarian failure, which is easily determined by an increase in serum gonadotropin levels (FSH and LH). Ovarian failure before menarche will prevent the development of the secondary sex characteristics as the patient gets older. Loss of ovarian function at any age afterward causes menopausal symptoms, including vasomotor instability (heat waves), fatigue, irritability, anxiety, vaginal dryness, decreased libido and breast atrophy. Opposite health results of POF include osteoporosis, cardiovascular diseases, impaired fecundity and psychosexual dysfunction (Stroud et al., 2009).

It is an openly held view that the mammalian neonatal ovary consists of a finite stockpile of non-growing primordial follicles each includes an oocyte arrested at the diplotene step of meiotic prophase (Greenfeld \& Flaws, 2004; Kerr et al., 2006; Said et al., 2014 and Telfer et al., 2005). Ionizing radiation holds a threat to oocytes leading to their damage (Mahran et al., 2015). Any harm to the dividing granulosa cells (GC) that line and support the developing follicles will affect the viability of the maturing oocytes. Disability of the follicle to develop mature oocytes available for ovulation marks the loss of ovarian function. The GCs seem to be the first goal for the radiation injury. Within a few hours of irradiation, before any changes in the oocytes are detectable, pyknosis- showing cell death- can be seen in GCs with enough loss ofGCs, the oocyte loses viability and the follicle atrophies (Rubin \& Casarett, 1986). The radiation sensitivity of the ovaries is based on many factors such as developing stage of cell, animal species involved, dose of irradiation, dose-rate used and at post irradiation time (Aurora et al., 2012).

In the present study, lower estradiol levels and higher FSH concentration were recorded in the irradiated group and the ovary weight was significantly reduced. The loss of follicles and folliculogenesis leads to disordered hormone secretion as well as the abnormal morphology and function of the ovarian effectas shown in the histological examination. This is in agreement with the findings of Powell et al. (1994), who stated that ovarian failure comes with low serum levels of estradiol and elevated FSH level and leads to infertility.

Hypersecretion of FSH and LH as observed after whole body gamma irradiation might result either from the activation of the hypothalamic pituitary axis or as a positive feedback mechanism in response to the lowered levels of estradiol and progesterone in serum. Also, radiation induced a damage of the central nervous system that may be reflected on hormonal secretion (Saleh et al., 1988).

Estrogen regulates gonadotropins release. Also, growth of ovarian follicles ovulation and the number of pre-ovulatory follicles are regulated by secretion of LH and FSH. It has been indicated that estrogen has significant antioxidant effects at high concentrations (Ogunro et al., 2014).

On the other hand, irradiation caused an elevation in the oxidative stress markers via an increase in the $\mathrm{H}_{2} \mathrm{O}_{2}$ concentration and decrease the GPx activity in the ovary. This is accordance with Noda et al. (2012) who reported that increased ROS level and decreased antioxidant enzyme activity combined together to impair the progesterone secretion.

Ionizing radiation can directly disrupt the DNA and result in chemical and biological changes in living cells, which initiates physiological changes or cell death (Spitz et al., 2004). Besides, indirectly, through the radiolysis of waterit can produce reactive oxygen species (ROS) that may damage nucleic acids, proteins, and lipids (Hall \& Giaccia, 2006). When attacked by ROS, bases in DNA can be oxidized, such as the oxidation of deoxyguanosine $(\mathrm{dG})$ to 8-hydroxy deoxyguanosine (8-OHdG) (Lindahl, 1993), which is higher in aging oocytes (Salmon et al., 2010).

ROS could affect physiological functions of female reproductive system tracts and has been implicated in ovarian follicles apoptosis under influence of external chemical and physical factors (Agarwal et al., 2012).

The current study demonstrated that irradiation caused upregulation of cytochrome C, P53 and caspase 3 expressions. This result 
is in agreement with Gao et al. (2007), who reported that X-irradiation caused oxidative stress and apoptosis in mouse ovarian granular cell. Oxidative stress is recognized as a strong mediator of apoptosis (Baynes \& Thorpe, 1999), and mitochondria play an important role in the apoptotic process (Buttke \& Sandstrom, 1994).

According to England \& Cotter (2005) increase of ROS level leads to release of mitochondrial cytochrome $\mathrm{C}$ and triggering of apoptosis by activating caspase3. Cell apoptosis is closely associated with the initiation of follicular atresia and luteal cell death (Hussein, 2005).

As a consequence, thiols such as GSH and other antioxidant enzymes compete with the oxidation induced by irradiation, chemically reduce the free radicals and repair the damage (Navarro et al., 1997). Thus, it was observed in the present study that the administration of Ferulic acid before irradiation minimized the damages caused by irradiation (via increased serum E2, ovarian GPx and decreased serum FSH\&LH, ovarian $\mathrm{H}_{2} \mathrm{O}_{2}$ and apoptotic markers) and improved the histological structure of the ovaries and uterus.

Ferulic acid displayed antioxidant and antiapoptotic activities and enhanced cellular stress response in the organ of Corti of guinea pigs exposed to noise (Fetoni et al., 2010). Furthermore, Calabrese and his co-workers successfully demonstrated the antioxidant and cytoprotective effects of Ferulic acid ethyl ester on human dermal fibroblasts (Calabrese et al., 2008).

Ferulic acid can accept an extra electron from superoxide radicals, thus stopping the free radical chain reaction and ROS generation (Srinivasan et al., 2006). Toda et al. (1991) recorded that the reactive oxygen species scavenging effect of Ferulic acid was similar to that of superoxide dismutase. In this study, FA treatment prior to irradiation safely decreased $\mathrm{H}_{2} \mathrm{O}_{2}$ and increased the activity of GPX. FA scavenged most of the ROS, so less ROS can interpose with the membrane lipid. Sequentially, FA could return the intracellular redox balance, accordingly, FA can modulate the harm created by irradiation in the ovary and uterus.

It was noted that Ferulic acid administration alone significantly increased some of the oxidative stress markers. Depending on that, ferulic acid as phenolic compound is antioxidant and is readily oxidized in aqueous media and form hydrogen peroxide (Halliwell \& Whiteman, 2004). Moreover, de Boer et al. (2006) stated that quercitin, a phenolic compound inhibits silent information regulators (SIRT1) activity due to its ability to form SIRT 1 inhibatory metabolites. This was in accordance with EL-Mesallamy et al. (2018). Inhibition of SIRT1 decreases cellular resistance to oxidative stress, activates both $\mathrm{NF}_{\text {}}$ $\mathrm{kB} \&$ proinfilamatory cytokines and promotes cellular apoptosis (Chung et al., 2010).

Considering the overall results, this study indicates that Ferulic acid has a protective effect against irradiation induced ovarian failure through its antioxidant and antiapoptotic activities. Thus, it could be used to slow the progression of the ovarian failure.

Acknowledgments: The authors would like to express their deep appriciation to the staff members of the Gamma Irradiation Unit, NCRRT for their generous support in carrying out the experimental irradiation. Appriciation and thanks are extended to Dr. Adel Bakeer Kholoussy, Professor of Pathology, Cairo University, Egypt, for his efforts in the histopathological examination.

\section{Conflict of interest}

The authors declare that they have no conflict of interest.

\section{References}

Agarwal, A., Aponte-Mellado, A. and Premkumar, B.J., et al. (2012) The effects of oxidative stress on female reproduction: A review. Reprod. Biol. Endocrinol. 10, 49.

Aurora, R.H., Francisca, G. and Montserrat, G.C. (2012) Radiobiology and Reproduction: What can we learn from mammalian females? Genes, 3, 521-544.

Banchroft, J.D., Stevens, A. and Turner, D.R. (1996) "Theory and Practice of Histological Techniques". $4^{\text {th }}$ ed. Churchil Livingstone, New York, London, San Francisco, Tokyo.

Baynes, J.W. and Thorpe, S.R. (1999) Role of oxidative stress in diabetic complications: A new perspective on an old paradigm. Diabetes, 48, 1-9. 
Braw, R.H. and Tsafriri, A. (1980) Effect of PMSG on follicular atresia in the immature rat ovary. Journal of Reproduction and Fertility, 59(2), 267-72.

Britt, K.L., Drummond, A.E., Cox, V.A., Dyson, M., Wreford, N.G., Jones, M.E., Simpson, E.R. and Findlay, J.K. (2000) An age-related ovarian phenotype in mice with targeted disruption of the Cyp 19 (aromatase) gene. Endocrinology, 141(7), 2614-23.

Buttke, T.M. and Sandstrom, P.A. (1994) Oxidative stress as a mediator of apoptosis. Immunol. Today, 15, 7-10.

Calabrese, V., Calafato, S. and Puleo, E., et al. (2008) Redox regulation of cellular stress response by ferulic acid ethyl ester in human dermal fibroblasts: Role of vitagenes. Clin. Dermatol. 26, 358-363.

Chung, S., Yao, H., Caito, S., Hwang, J.W., Arunachalam, G. and Rahman, I. (2010) Regulation of SIRT1 in cellular functions: Role of polyphenols. Archives of Biochemistry and Biophysics, 501(1), 79-90.

Das, U., Manna, K. and Sinha, M., et al. (2014) Role of Ferulic acid in the amelioration of ionizing radiation induced inflammation: A murine model. PLoS ONE, 9(5), 599-615.

de Boer, V.C., de Goffau, M.C., Arts, I.C., Hollman, P.C. and Keijer, J. (2006) SIRT1 stimulation by polyphenols is affected by their stability and metabolism. Mechanisms of Ageing and Development, 127(7), 618-627.

Dehghan, H., Mozdarani, A. and Khoradmehr, S.M., et al. (2014) Evaluation of embryo quality after concurrent use of ovarian stimulating hormones and gamma irradiation. Iranian Journal of Reproductive Medicine, 12(8), 573-580.

EL-Mesallamy, H.O., Gawish, R.A., Sallam, A.A.M., Fahmy, H.A. and Nada, A.S. (2018) Ferulic acid protects against radiation-induced testicular damage in male rats: Impact on SIRT1 and PARP1. Environmental Science and Pollution Research, 25(7), 6218-6227.

England, K. and Cotter, T.G. (2005) Direct oxidative modifications of signaling proteins in mammalian cells and their effects on apoptosis. Redox Rep. 10, 237-245.
Fetoni, A.R., Mancuso, C. and Eramo, S.L.M., et al. (2010) In vivo protective effect of Ferulic acid against noise induced hearing loss in the guinea pig. Neuroscience, 169, 1575-1588.

Flecknell, P.A. (1987) "Laboratory Animals Anasethia: An Introduction for Research Workers and Technicans". Academia Press, London, San Diego, $125 \mathrm{p}$.

Fossati, P., Prencipe, L. and Bertl, G. (1983) Enzymic creatinine assay: A new colorimetric method based on hydrogen peroxide measurement. Clin. Chem. 29(8), 1494-1496.

Fulcher, R.G. (1983) Fluorescence microscopy of cereals in, new frontiers in food microstructure, ed. By American Association of cereal chemists, Ottawa, Canada, pp. 167-175.

Gao, W., Liang, J.X. and Ma, C., et al. (2007) The protective effect of $\mathrm{N}$-acetylcysteine on ionizing radiation induced ovarian failure and loss of ovarian reserve in female mouse. Bio. Med. Research International, 41(7), 61-70.

Grdina, D.J., Murley, J.S. and Kataoka, Y. (2002) Radioprotectants: Current status and new directions. Oncology, 63, 2-10.

Green, D.M., Sklar, C.A. and Boice, J.D. (2009) Ovarian failure and reproductive outcomes after childhood cancer treatment: Results from the childhood cancer survivor study. Journal of Clinical Oncology, 27(14), 2374-2381.

Greenfeld, C. and Flaws, J.A. (2004) Renewed debate over postnatal oogenesis in the mammalian ovary. Bioessays, 26, 829-832.

Hall, E.J. and Giaccia, A.J. (2006) "Radiobiology for the Radiologist", Lippincott Williams \& Wilkins, Philadelphia, Pa, USA, $6^{\text {th }}$ ed.

Halliwell, B. and Whiteman, M. (2004) Measuring reactive species and oxidative damage in vivo and in cell culture: How should you do it and what do the results mean?. British Journal of Pharmacology, 142(2), 231-255.

Hussein, M.R. (2005) Apoptosis in the ovary: Molecular mechanisms. Hum. Reprod Update, 11, 162-77.

Ibrahim, I.A., Shousha, W.Gh. and El-Sayed, E.M., 
et al. (2015) Ramadan nasturtium officinale and raphanus sativus crude extracts protect ovary from radiation-induced DNA damage. World Journal of Pharmacy and Pharmaceutical Sciences, 4(4), 80102.

Kerr, J.B., Duckett, R. and Myers, M., et al. (2006) Quantification of healthy follicles in the neonatal and adult mouse ovary: evidence for maintenance of primordial follicle supply. Reproduction, 132, 95-109.

Lindahl, T. (1993) Instability and decay of the primary structure of DNA. Nature, 362(6422), 709-715.

Mahran, Y.F., El-Demerdash, E., Nada, A.S., El-Naga, R.N., Ali, A.A. and Abdel-Naim, A.B. (2015) Growth hormone ameliorates the radiotherapyinduced ovarian follicular loss in rats: Impact on oxidative stress, apoptosis and IGF-1/IGF-1R axis. PLoS One, 10(10), 1-22.

Nair, C.K.K., Parida, D.K. and Nomura, T. (2001) Radioprotectors in radiotherapy. J. Radiat. Res. 42, 21-37.

Navarro, J., Obrador, E. and Pellicer, J.A., et al. (1997) Blood glutathione as an index of radiation-induced oxidative stress in mice and humans. Free Radic Biol. Med. 22, 1203-1209.

Noda, Y., Ota, K. and Shirasawa, T., et al. (2012) Copper/zinc superoxide dismutase insufficiency impairs progesterone secretion and fertility in female mice. Biology of Reproduction, 86(1), 1-8.

Ogunro, P.S., Bolarinde, A.A. and Owa, O.O., et al. (2014) Antioxidant status and reproductive hormones in women during reproductive, perimenopausal and postmenopausal phase of life. Afr. J. Med. Sci. 43(1), 49-57.

Ou, S. and Kwok, K.C. (2004) Ferulic acid: Pharmaceutical functions, preparation and applications in foods. J. Sci. Food Agric. 84, 12611269.

Paglia, D.E. and Valentine, W.N. (1967) Studies on the quantitative and qualitative characterization of erythrocyte glutathione peroxidase. J. Lab. Clin. Med. 70, 158-169.

Pfaffl, M.W. (2001) A new mathematical model for relative quantification in real-time RT-PCR.
Nucleic Acids Res. 29, e45.

Powell, C.M., Taggart, R.T. and Drumheller, T.C., et al (1994) Molecular and cytogenetic studies of an X; autosome translocation in a patient with premature ovarian failure and review of the literature. Am. J. Med. Genet. 52(1), 19-26.

Roy, S., Metya, S.K. and Rahaman, N., et al. (2013) Ferulic acid in the treatment of post-diabetes testicular damage relevance to the down regulation of apoptosis correlates with antioxidant status via modulation of TGF- $\beta 1$, IL- $1 \beta$ and Aktsignaling. Cell Biochem. Funct. 32, 115.

Rubin, P. and Casarett, G.W. (1986) The female genital tract. In: "Clinical Radiation Pathology", Rubin, P., Casarett, G.W. (Eds.), pp. 396-422. Philadelphia:W.B. Saunders.

Said, R.S., Nada, A.S. and El-Demerdash, E. (2012) Sodium selenite improves folliculogenesis in radiation-induced ovarian failure: A mechanistic approach. PLoS ONE, 7(12), e50928.

Said, R.S., Badr, A.M., Nada, A.S. and El-Demerdash, E. (2014) Sodium selenite treatment restores longlasting ovarian damage induced by irradiation in rats: Impact on oxidative stress and apoptosis. Reproductive Toxicology, 43, 85-93.

Saleh, S., Roushdy, H.M. and Abde Aziz, M.T., et al (1988) Radiation-induced disorders in ovarian function. Egypt. J. Rad. Sci. Applic. 5(1), 75.

Salmon, A.B., Richardson, A. and P'erez, V.I. (2010) Update on the oxidative stress theory of aging: Does oxidative stress play a role in aging or healthy aging? Free Radical Biology\& Medicine, 48(5), 642-655.

Sinha, M., Das, D.K., Manna, K. and Datta, S., et al. (2012) Epicatechin ameliorates ionising radiationinduced oxidative stress in mice liver. Free Radic. Res. 46, 842-849.

Sőnmezer, M. and Oktay, K. (2008) Assisted reproduction and fertility preservation techniques in cancer patients. Current Opinion in Endocrinology, Diabetes and Obesity, 15(6), 514-522.

Spitz, D.R., Azzam, E.I. and Li, J.J., et al. (2004) Metabolic oxidation/reduction reactions and cellular responses to ionizing radiation: a unifying concept in stress response biology. Cancer and Metastasis 
Reviews, 23(3-4), 311-322.

Srinivasan, M., Sudheer, A.R. and Menon, V.P. (2007)

Ferulic acid: Therapeutic potential through its antioxidant property. J. Clin. Biochem. Nutr. 40, 92100.

Srinivasan, M., Sudheer, A.R. and Pillai, K.R., et al. (2006) Influence of ferulic acid on $\gamma$-radiation induced DNA damage, lipid peroxidation and antioxidant status in primary culture of isolated rat hepatocytes. Toxicology, 228, 249-258.

Stroud, J.S., Mutch, D. and Rader, J., et al. (2009)
Effects of cancer treatment on ovarian function. Fertility and Sterility, 92(2), 417-427.

Telfer, E.E., Gosden, R.G. and Byskov, A.G., et al. (2005) On regenerating the ovary and generating controversy. Cell, 122, 821-822.

Toda, S., Kumura, M. and Ohnishi, M. (1991) Effects of phenolic carboxylic acids on superoxide anion and lipid peroxidation induced by superoxide anion. Plant Med. 57, 8-10.

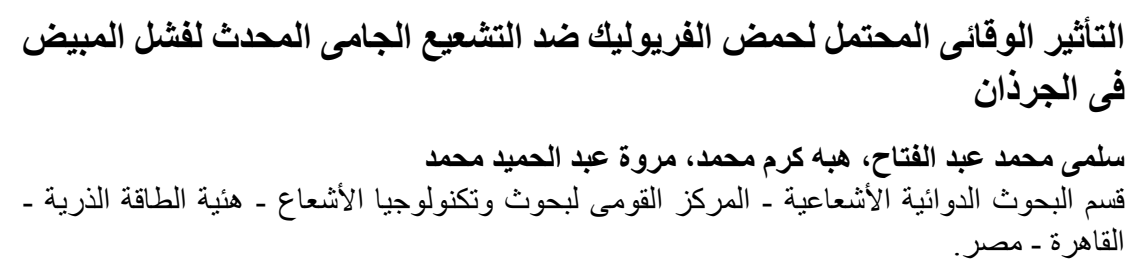

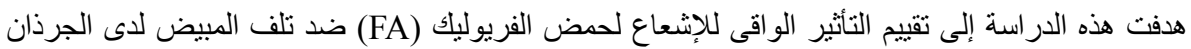

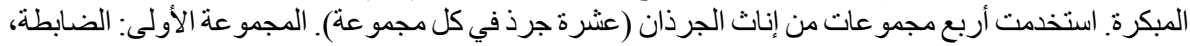

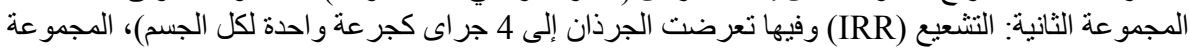

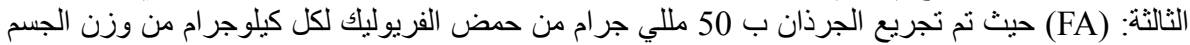

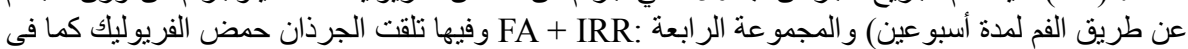



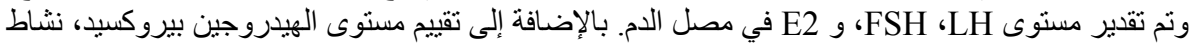

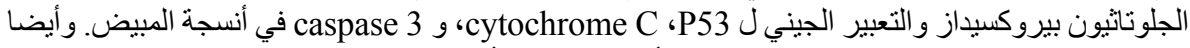
تم إجر اء الفحص النسيجي للمبيض و الرحم. و لقد أظهرت النتائج أن التشعيع الجامى تسبب في إرتفاع مستويات

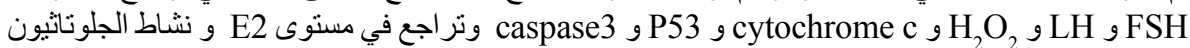

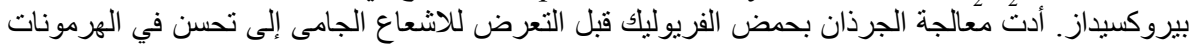

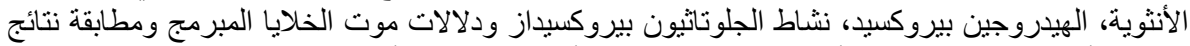

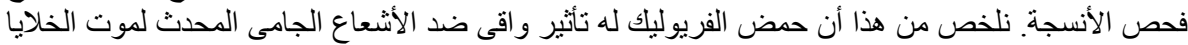
المبرمج فى مبيض الجرذان و أضطر اب مستوى الهرمونات الأنثوية في مصل الذان. 